\title{
FORMULATION AND EVALUATION OF CHITOSAN-POLYPYRROLE NANOCOMPOSITES FOR CONTROLLED RELEASE OF ANTICANCER DRUG DOXORUBICIN
}

\author{
DILLIP KUMAR BEHERA*, KAMPAL MISHRA \\ Department of Physics, SOA University, Odisha, India \\ Email: dilip@nsarf.in \\ Received: 30 Oct 2018, Revised and Accepted: 12 Feb 2019
}

\begin{abstract}
Objective: The purpose of the present study was a characterization of chitosan (CS)-polypyrrole (PPY) nanocomposites for controlled release of anticancer drug doxorubicin (DOX).

Methods: Chitosan crosslink with PPY with montmorillonite (MMT) called as (CS-PPY/MMT) were formulated using the solvent casting method. The prepared nanocomposites were characterized by X-Ray Diffraction Analysis (XRD), tensile strength, scanning electronic microscope (SEM).

Results: The XRD result confirmed that the CS-PPY/MMT possessed crystal structure. The nanocomposites CS-PPY/MMT-4 were showed a homogenous morphology. The Water uptake and swelling ratio of the CS-PPY and CS-PPY/MMT were found to decrease with increase in the concentration of clay. Mechanical properties of the CS-PPY and CS-PPY/MMT were assessed in terms of tensile strength and extensibility using texture analyzer. Increase in tensile strength and reduction in extensibility was reported with an increase in the nanoclay content. In vitro drug release study on CS-PPY and CS-PPY/MMT indicated pronounced sustained release of doxorubicin by the incorporation of clay particles in CSPPY/MMT. It was observed that during the first 60 min of the dissolution study, the CS-PPY/MMT-4 film showed just $79.32 \pm 0.56 \%$ drug release as while the CS-PPY-1, CS-PPY/MMT-2 and CS-PPY/MMT-3 films showed a release of 53.79 $\pm 1.23 \%, 63.51 \pm 1.24 \%$ and $68.15 \pm 2.38 \%$ respectively.
\end{abstract}

Conclusion: CS-PPY/MMT nanocomposite films exhibited improved mechanical and sustained drug release properties than CS-PPY. The combination of biodegradable polymeric chains and clay reinforcement can be applied to achieve the desired combination of properties of materials used as a biosensor for diverse biomedical applications.

Keywords: Chitosan, Polypyrrole, Montmorillonite nanocomposites, Doxorubicin, Drug delivery

(C) 2019 The Authors. Published by Innovare Academic Sciences Pvt Ltd. This is an open-access article under the CC BY license (http://creativecommons.org/licenses/by/4.0/) DOI: http://dx.doi.org/10.22159/ijap.2019v11i2.30544

\section{INTRODUCTION}

Today polymeric nanomaterials have created an excellent, outstanding field in the pharmaceutical and medical field due to its extra amazing physical, chemical and biological properties [1, 2]. Chitosan is a most popular carbohydrate polysaccharide polymer which is easily available in Indian market. In recent year, Chitosan is known as biomaterials for drug delivery due to nontoxic, biocompatibility, hydrophilic nature, low molecular weight, costeffective, environmentally friendly properties, etc. respectively. Nowadays the enhancement of chitosan properties in micro and nano form is a new ambition for future research. Also, interesting properties of chitosan and its derivatives with mucoadhesion nature is going to the good potentiality of drug delivery system [3-5].

Conducting polymers have been extensively studied in recent years because of their special properties and promising potential applications such as electromagnetic interference shielding, biosensors, actuators, field emission, and so forth. Polypyrrole is unique among the family of conducting polymers due to its good environmental stability, easy synthesis, reversible doping and redox properties [6]. However, the macroscopic appearance of the asprepared PPy is generally either an insoluble granular solid or an intractable brittle thin film.

It is known that the properties of the polymer/clay composite are strongly affected by the addition of surfactant(s) into the composite. On those systems, the typical molecules are long chain alkyl quaternary ammonium chlorides, which are easily incorporated into the clay structure. Large molecule additions, except the use of longchain alkyl quaternary amines or polyglycol to manipulate the composite properties, are seldom studied [7].

Present study was designed to characterize the CS-PPY with MMT and CS-PPY polymer composites for controlled release of anticancer drug doxorubicin. The CS-PPY and CS-PPY/MMT films were evaluated in terms of SEM, FTIR, XRD, Mechanical, physical, TGA, swelling and in vitro release study of an anticancer drug Doxorubcin.

\section{MATERIALS AND METHODS}

\section{Chemicals}

Chitosan (molecular weight $\sim 250 \mathrm{kDa}$ and $\sim 93.0 \% \mathrm{DDA}$ ) and polypyrrole (PPY) were purchased from Himedia Pvt Ltd. Montmorilonite was purchased from Southern Clay, USA. All other reagents and chemicals were used as the analytical grade. Millipore water was used in the entire experimental work.

\section{Drug}

Doxorubicin hydrochloride $(543.52 \mathrm{~g} / \mathrm{mol}) \quad \mathrm{C}_{27} \mathrm{H}_{29} \mathrm{NO}_{11} \quad$ was obtained as gifts (Newredmars Education, Pvt. Ltd India).

\section{Preparation of CS-PPY/MMT blends and their nanocomposites}

The CS-PPY/MMT films were prepared using CS, MMT and PPY. CS solution was prepared by dissolving CS in a $2 \%(\mathrm{v} / \mathrm{v})$ aqueous acetic acid solution, followed by centrifuging to remove the insoluble material. MMT has first swelled in $2 \%(\mathrm{v} / \mathrm{v})$ aqueous acetic acid solution and then added to CS solution with continuous stirring (300 $\mathrm{rpm}$ ) at $60^{\circ} \mathrm{C}$ for $4 \mathrm{~h}$. PPY was added as a conducting polymer agent. CS-PPY/MMT films were prepared using different ratios of CS, PPY and MMT as shown in table no.1. These were coded as CS-PPY-1, CSPPY/MMT-2, CS-PPY/MMT-3, CS-PPY/MMT-4 representing different wt $\%$ of MMT content $(1 \%, 3 \%, 5 \%)$ respectively $[8,9]$. The formulation codes for different films are shown in table no. 1and fig. 1.

\section{Drug loading}

Drug content pre-weighed a sample of film was placed in $100 \mathrm{ml}$ of phosphate buffer ( $\mathrm{pH}$ 7.4) and agitated on a mechanical shaker for 6 h. Solution was filtered and analyzed spectrophotometrically at 224 nm. 
Table 1: Sample preparation of CS-PPY-MMT nanocomposites $(n=3)$

\begin{tabular}{llll}
\hline Sample & CS (in gms) & PPY (\%) & MMT (wt \%) \\
\hline CS-PPY-1 & 2.5 & 1 & - \\
CS-PPY/MMT-2 & 2.5 & 1 & 1 \\
CS-PPY/MMT-3 & 2.5 & 1 & 3 \\
CS-PPY/MMT-4 & 2.5 & 1 & 5 \\
\hline
\end{tabular}

${ }^{*} \mathrm{CS}$ molecular weight in $\mathrm{kDa} . \mathrm{n}=3$ and data are given in mean $\pm \mathrm{SD}$, Where CS: Chitosan, PPY: polypyrrole, MMT: Montmorilonite

\section{Loading efficiency}

$$
\mathrm{LE}=\frac{\mathrm{W}_{\mathrm{a}}}{\mathrm{W}_{\mathrm{d}}} \mathrm{X} 100 \%
$$

Loading content

$$
\mathrm{LC}=\frac{\mathrm{W}_{\mathrm{a}}}{\mathrm{W}_{\mathrm{np}}} \mathrm{X} 100 \%
$$

Where LC: Loading content;

LE: Loading efficiency,

$\mathrm{W}_{\mathrm{a}}$ : quantity of drug found in the drug-loaded nanocomposite,

$\mathrm{W}_{\mathrm{d} \text { : }}$ quantity of drug beginning added into the system

$\mathrm{W}_{\mathrm{np}}$ : quantity of drug-loaded nanocomposite.

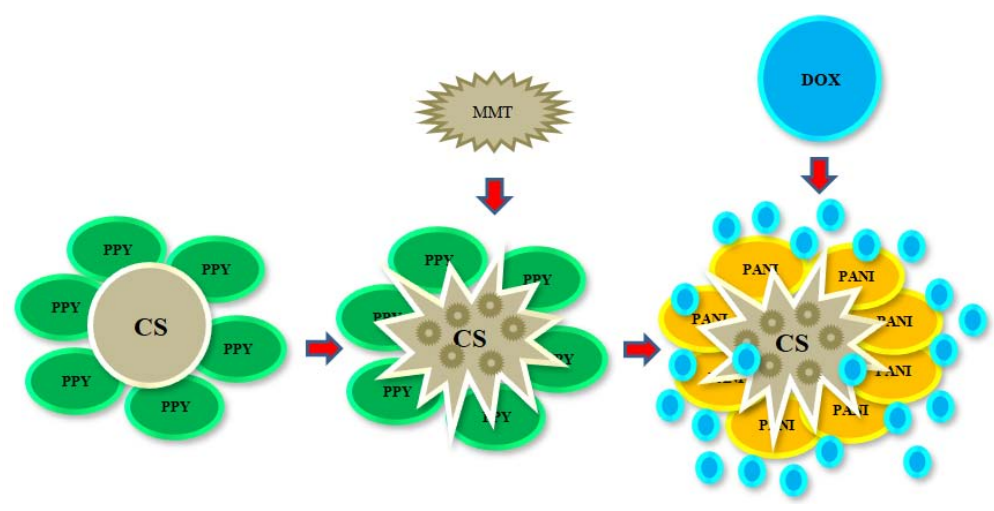

Fig. 1: Schematic representation of DOX-loaded CS-PPY/MMT nanocomposite

\section{Characterization}

\section{Scanning electron microscopy (SEM)}

Liquid nitrogen was used for freezing the CS-PPY, and CS-PPY/MMT sheets and then snapped quickly, and then the fractured surface was sputtered with gold and investigated with a Scanning electron microscope instrument (JSM-5900LV) using an acceleration voltage of $20 \mathrm{kV}$.

\section{X-ray diffraction (XRD)}

D8 Advance Diffractometer (Bruker, U. S. A.) equipped with a $\mathrm{CuK \alpha}$ radiation source $(\lambda=0.154 \mathrm{~nm})$ was utilized for X-ray diffraction. The diffraction data were obtained from $2 \theta=1^{\circ}-80^{\circ}$.

\section{Mechanical properties}

The tensile properties of the sample were incorporated on a universal testing machine (CMT4104, Shenzhen SANS Test Machine Co. Ltd, Central Institute of Plastics Engineering and Technology (CIPET), and Odisha) with a tensile rate of $5 \mathrm{~mm} / \mathrm{min}$.

\section{Swelling studies}

The swelling study is calculating the extent of water uptake or degree of dehydration. It is using at the time of fabrication of polymer film. It has been shown that most of the mucoadhesive polymers undergo some degree of swelling after hydration, which is necessary to initiate intimate contact of the nanocomposites with the mucosal surface. These studies for monitoring of swelling index of the nanocomposites were regulated in the phosphate buffer of $\mathrm{pH}$ 7.4. The CS-PPY/MMT nanocomposites (surface area: $1.75 \mathrm{~cm}^{2}$ ) was weighed and put in a pre-weighed stainless steel wire sieve of approximately $900 \mu \mathrm{m}$ mesh. The mesh containing the required quantity of nanocomposites was then submerged in $15 \mathrm{ml}$ of the phosphate buffer medium contained in a porcelain dish [10]. At appropriated time intervals, the stainless steel mesh was removed from the dish, and the excess moisture was removed by carefully clean it off with absorbent tissue, then it was reweighed. The enhancement of the weight of the polymer matrix was calculated at each time interval until a constant weight was calculated. The degree of the swelling index of the matrix was analyzed using the following formulation:

$$
\mathrm{S} . \mathrm{I}=\frac{\mathrm{W}_{\mathrm{t}}-\mathrm{W}_{0}}{\mathrm{~W}_{0}}
$$

Where S. I: Swelling Index,

$\mathrm{w}_{\mathrm{t}}$ : weight of film at time' $\mathrm{t}$ '

$\mathrm{w}_{0}$ : weight of the film at time 0

\section{RESULTS AND DISCUSSION}

\section{Sem}

Fig. 2 shows SEM of CS-PPY-1 and CS-PPY/MMT-4 at 5000X magnifications. The nanocomposites CS-PPY/MMT-4 were showed a homogenous morphology in comparison with the blending polymer CS-PPY without clay. The CS-PPY/MMT-4 was identified the best nanocomposite polymer. The microstructure obtained smooth homogenous for CS-PPY/MMT-4 comparing with pure CS and CSPPY. Additionally, the surface morphology of CS-PPY/MMT-4 was demonstrated more exfoliated with homogenous form comparing with other percentages of MMT. This might boost the surface modification of blending polymer nanocomposites [11]. 

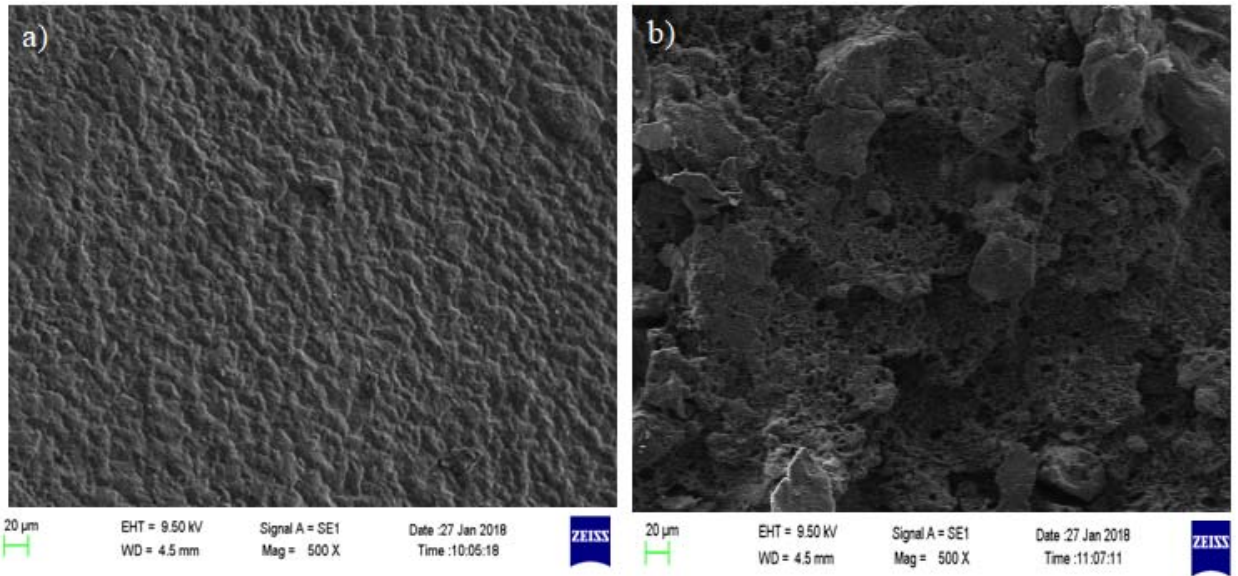

Fig. 2: SEM of CS-PPY (a) and CS-PPY/MMT-4 (b)

\section{XRD}

Fig. 3a the X-ray diffraction pattern of the MMT with intense peak appearing near $2 \theta=4.85^{\circ}$. In fig. $3 \mathrm{~b}$ the diffraction peaks of CS are located around $10.5^{\circ}, 19.2^{\circ}$. They are very weak, indicating low crystallinity. Additionally, the diffraction peaks of DOX are located at $2 \theta=9.12^{\circ}, 10.34^{\circ}, 21.13^{\circ}, 28.13^{\circ}, 31.10^{\circ}, 37.23^{\circ}, 47.12^{\circ}$ and $56.10^{\circ}$. This was the high crystalline structure with the strong peak for DOX. However, in the CS-PPY-1 polymer shows two diffraction peaks at $2 \theta$ $=12.41^{\circ}, 17.11^{\circ}, 21.13^{\circ}, 20.08^{\circ}$ and $37.45^{\circ}$. Additionally, when MMT was added with CS-PPY polymer, the diffraction peaks of CSPPY/MMT-4 is located around $2 \theta=4.71^{\circ}, 9.29^{\circ}, 16.26^{\circ}, 21.71^{\circ}$, $36.14^{\circ}$ and $46.25^{\circ}[11,12]$. There is negligible difference between in comparison with CS-PPY/MMT-2, CS-PPY/MMT-3. In other hand DOX was added with CS-PPY/MMT-4, three new peaks were observed at $5.61^{\circ}, 9.49^{\circ}, 17.36^{\circ}, 23.41^{\circ}, 35.14^{\circ}, 45.35^{\circ}$ and $50.11^{\circ}$ indicating crystalline nature.

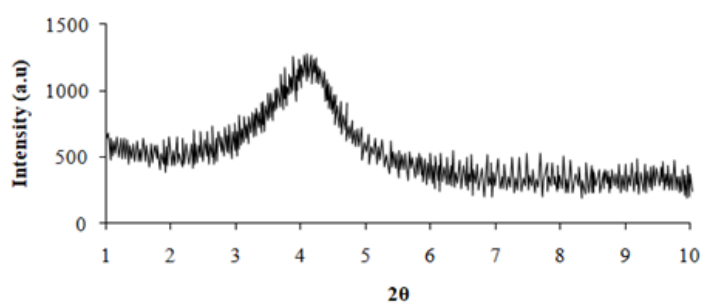

Fig. 3: (a) XRD of MMT

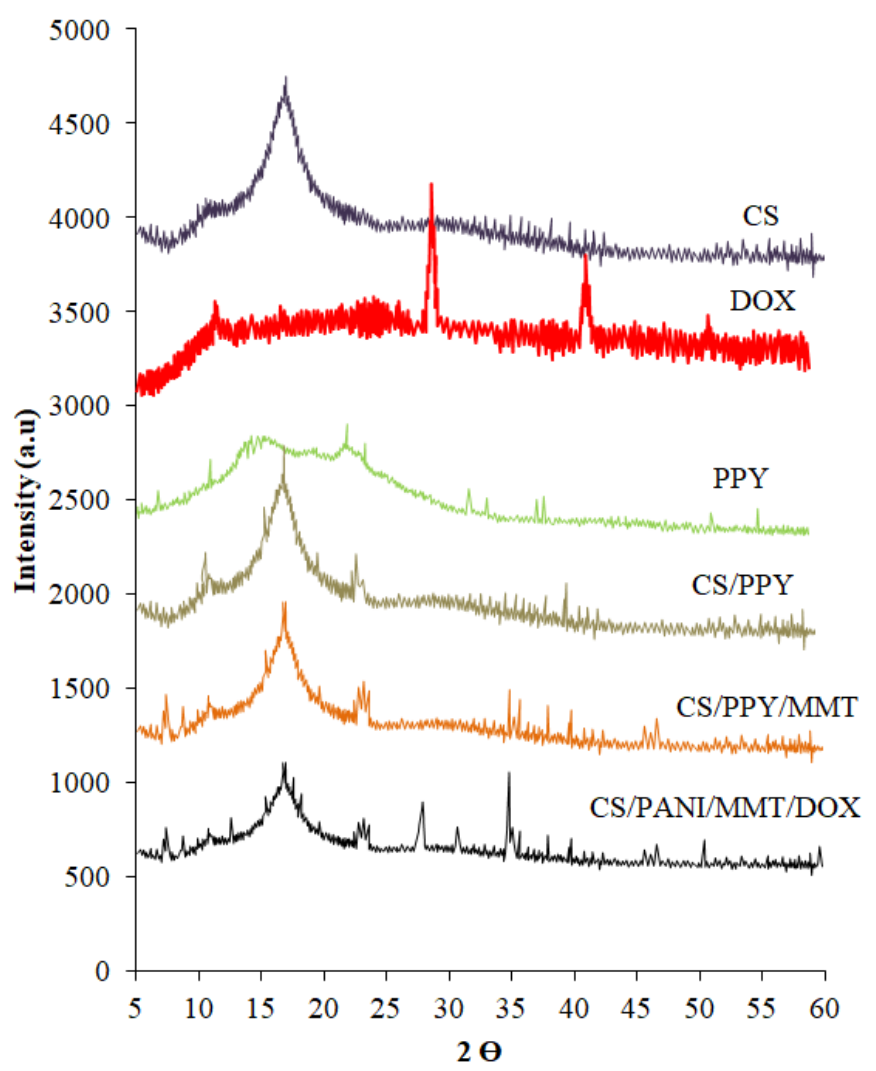

Fig. 3: (b) XRD of CS, and DOX, CS-PPY, CS-PPY/MMT-2, CS-PPY/MMT-3, CS-PPY/MMT-4 


\section{Mechanical properties}

The mechanical strength of a CS-PPY/MMT film was described in terms its tensile strength and percentage of elongation to break that is, extensibility in table no. 2. A significant influence of the MMT concentration on the mechanical properties of the films was observed. Tensile strength was observed to increase with an increase in the MMT content in the films. It was reported in fig. 4 that the tensile strength ranged from $21.13 \pm 1.26 \mathrm{~N} / \mathrm{mm}^{2}$ in pure CS film) to
$43.21 \pm 1.23 \mathrm{~N} / \mathrm{mm}^{2}$ (CS-PPY/MMT-4 film). The enhancement in tensile strength of the nanocomposites might be attributed to the high-aspect ratio and rigidity which results from the strong affinity between the biopolymer and nanoclay. As reported evident from literature, tensile strength values of CS-PPY/MMT nanocomposites increased significantly with increasing nanoclay concentration due to a possible strain-induced alignment of the nanoclay particle layers in the nanocomposites [12].

Table 2: Tensile strength and extensibility of CS-PPY/MMT films (n=3)

\begin{tabular}{lll}
\hline Sample & Tensile strength (MPa) & Extensibility \% \\
\hline CS & $21.13 \pm 1.26$ & $19.20 \pm 1.66$ \\
CS-PPY-1 & $25.12 \pm 1.23$ & $20.42 \pm 1.56$ \\
CS-PPY/MMT-2 & $34.21 \pm 2.15$ & $11.02 \pm 1.30$ \\
CS-PPY/MMT-3 & $27.06 \pm 1.02$ & $12.13 \pm 0.26$ \\
CS-PPY/MMT-4 & $43.21 \pm 1.23$ & $10.21 \pm 2.13$ \\
\hline
\end{tabular}

${ }^{*}$ CS molecular weight in kDa. $n=3$ and data are given in mean \pm SD, Where CS: Chitosan, PPY: polypyrrole, MMT: Montmorilonite, MPa: Megapascal Pressure Unit

The extensibility in fig. 5 ranged from $10.21 \pm 2.13$ (CS-PPY/MMT-4 film) to $12.13 \pm 0.26 \%$ (CS-PPY/MMT-3 film), whereas the pure CS film recorded extensibility of $19.20 \pm 1.66 \%$. The effect of MMT on the extensibility shows a significant decrease in elongation to break as the MMT concentration increases. The results were found to be in good agreement with the findings reported by Svoboda et al., Hasegawa et al. and Bangyekan et al. [13, 14].

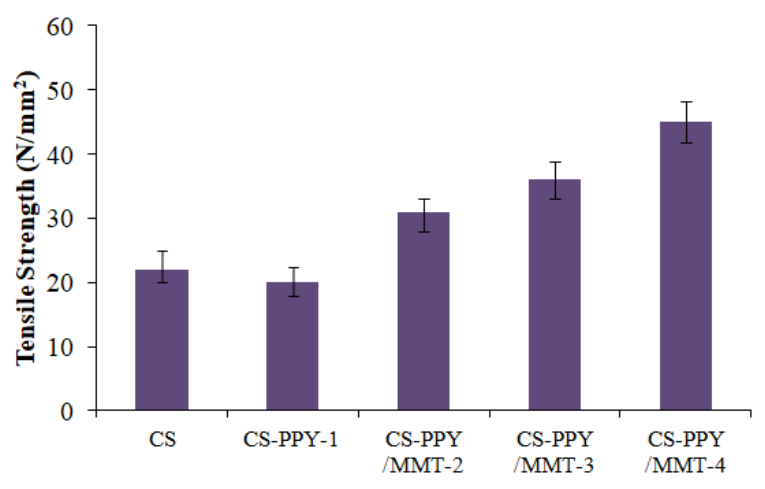

Fig. 4: Tensile strength of CS, CS-PPY, CS-PPY/MMT-2, CSPPY/MMT-3, CS-PPY/MMT-4 $n=3$, and data are given in mean \pm SD

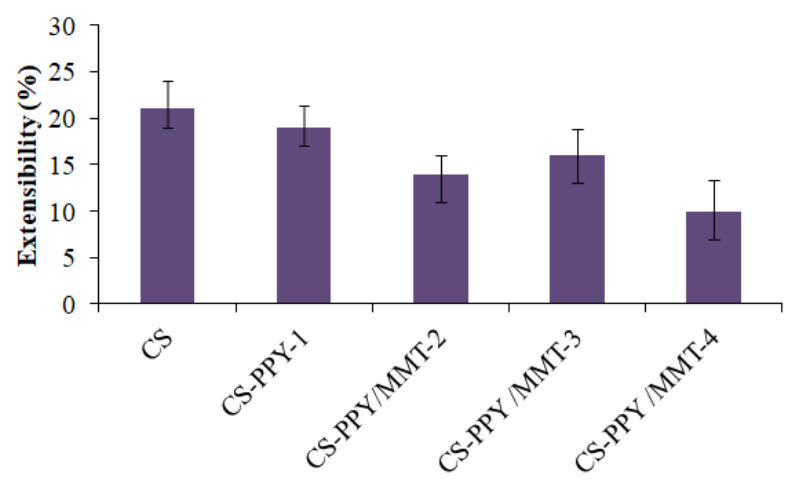

Fig. 5: Extensibility of CS-PPY/MMT films $n=3$ and data are given in mean $\pm S D$

\section{Physical properties}

The prepared CS-PPY/MMT were compact, smooth and without pores or imperfections. A synergistic effect of MMT for improving thermal stability, mechanical, and barrier properties of CS has been proposed. The evaluation of CS-PPY/MMT composite films in terms of various physicochemical properties, characterization FTIR and DSC studies and stability testing is discussed hereunder [15].

Table 3: Physical properties of CS-PPY/MMT composite $(n=3)$

\begin{tabular}{lllllll}
\hline Sample & Thickness & Drug content & $\begin{array}{l}\text { Weight } \\
\text { variation }\end{array}$ & $\begin{array}{l}\text { Moisture content } \\
\text { \% }\end{array}$ & $\begin{array}{l}\text { Moisture absorption } \\
\text { (\%) }\end{array}$ & $\begin{array}{l}\text { Folding } \\
\text { endurance }\end{array}$ \\
\hline CS-PPY-1 & $0.14 \pm 0.12$ & $86.81 \pm 0.11$ & $0.27 \pm 0.14$ & $2.76 \pm 0.11$ & $6.77 \pm 0.12$ \\
pH
\end{tabular}

${ }^{*} \mathrm{CS}$ molecular weight in $\mathrm{kDa}$. $\mathrm{n}=3$ and data are given in mean $\pm \mathrm{SD}$, Where CS: Chitosan, PPY: polypyrrole, MMT: Montmorilonite

Table 3 depicts various physicochemical properties of the prepared CS-PPY/MMT films. The polymeric combination of CS-PPY with MMT exhibited good film-forming properties and the method of casting of films was found to produce good films. The thickness of the films vary from $0.12 \pm 0.13$ to $0.33 \pm 0.42 \mathrm{~mm}$ while the drug content in the films ranges from $86.81 \pm 0.11 \%$ to $94.61 \pm 0.22 \%$. The weight of the films ranged from $0.27 \pm 0.14$ to $0.49 \pm 0.21 \mathrm{~g}$. The results indicated that the method selected for the preparation of films was capable of producing films with uniform weight, content and minimal film variability. The folding endurance was found to be ranging between
$250 \pm 1.15$ and $269 \pm 1.23$ indicating that the formulated films would maintain their integrity when applied to the skin. The $\mathrm{pH}$ of the films near about 7.4. Low moisture content is useful for the long term stability of the films. It also reduces the brittleness and protects the formulation from microbial contamination. Moisture content and moisture uptake studies indicated that the increase in the concentration of hydrophilic polymer was directly proportional to the increase in moisture content and moisture uptake of the films, whereas increase in the concentration of hydrophobic polymer lead to the decrease in moisture content and moisture uptake of the films. 


\section{Swelling ratio}

The swelling ratio studies performed on the films are shown in fig. 6. Similar to the water uptake studies in fig. 7, the swelling studies also showed a decrease in the swelling of the films with a decrease in the
CS concentration. The swelling ratio was reported to be in the order CS-PPY/MMT 4>CS-PPY/MMT-2>CS-PPY/MMT-3>CS-PPY/MMT-1. The behavior could be explained in terms that the MMT clay particles occupy the free space volume in the CS polymeric network thereby decreasing the volume available for swelling [16].

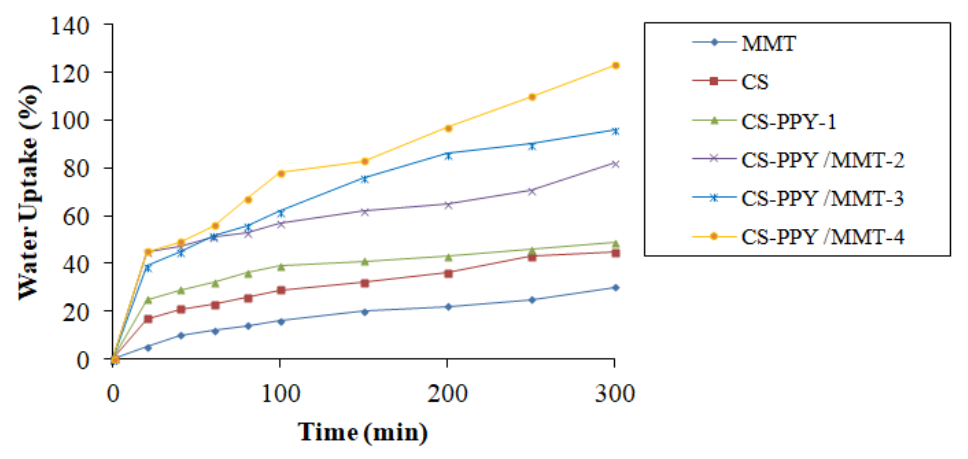

Fig. 6: Swelling ratio of CS, CS-PPY, CS-PPY/MMT-2, CS-PPY/MMT-3, CS-PPY/MMT-4 $n=3$ and data are given in mean \pm SD

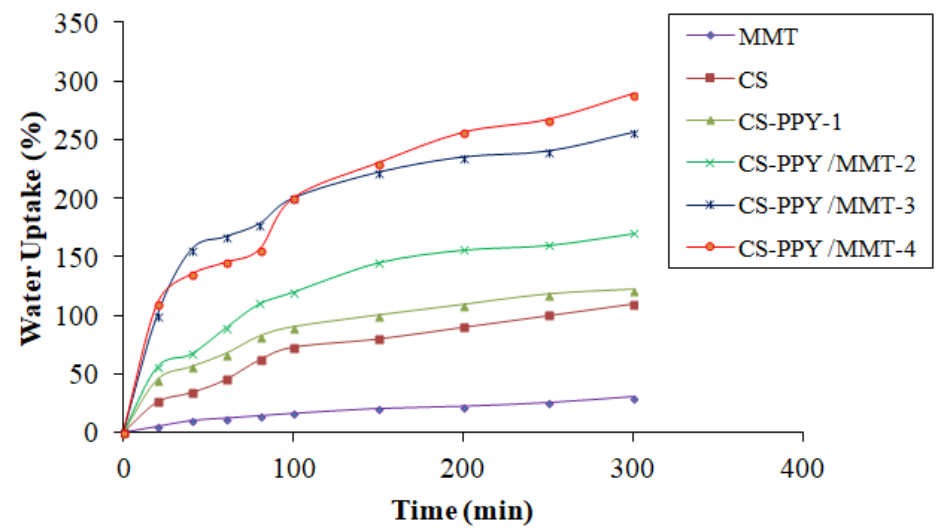

Fig. 7: Water uptake CS, CS-PPY, CS-PPY/MMT-2, CS-PPY/MMT-3, CS-PPY/MMT-4 $n=3$ and data are given in mean \pm SD

\section{In vitro release study}

The results obtained from the in vitro dissolution study of the films are presented in fig. 8 . The order of increased drug dissolution using the different approaches was as follows; CS-PPY/MMT-1 $>$ CSPPY/MMT-2>CS-PPY/MMT-3>CS-PPY-4. It was observed that during the first $60 \mathrm{~min}$ of the dissolution study, the CS-PPY/MMT-4 film showed just $79.32 \pm 0.56 \%$ drug release as while the CS-PPY-1, CSPPY/MMT-2, and CS-PPY/MMT-3 films showed a release of $53.79 \pm 1.23 \%, 63.51 \pm 1.24 \%$, and $68.15 \pm 2.38 \%$ respectively. Results of various film tests indicate that among the three samples used for the preparation of CS-PPY/MMT films, CS-PPY/MMT-4 and CSPPY/MMT-2 were more effective method than CS-PPY-1 and CSPPY/MMT-3. This is quite evident from the drug release behavior of the CS-PPY/MMT films after $8 \mathrm{~h}$ of dissolution study respectively.

CS-PPY/MMT-4 and CS-PPY/MMT-2 showed better-sustained release effects. This kind of behaviour is a result of the strong electrostatic interaction between the cationic charges of CS and the anionic charges of MMT $[17,18]$

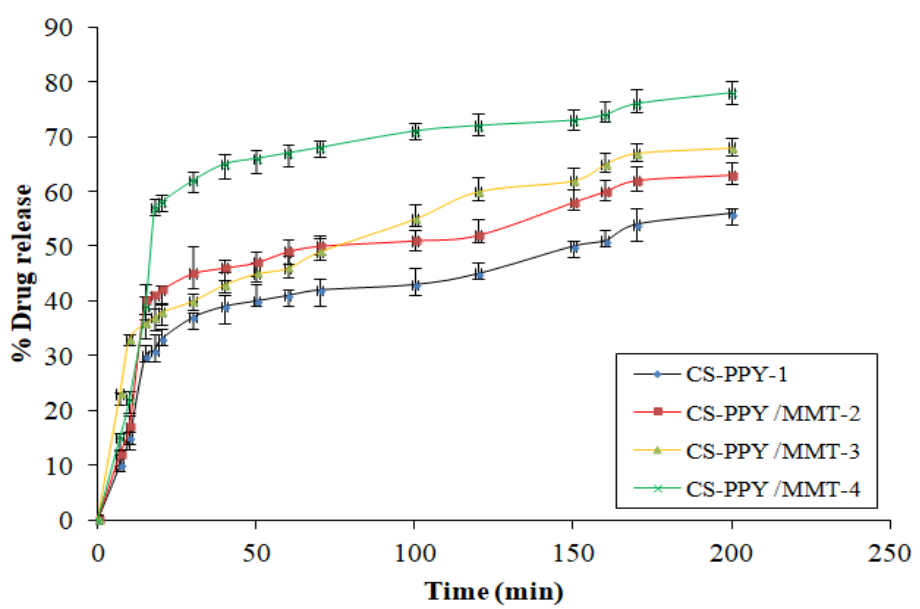

Fig. 8: In vitro drug release of CS-PPY/MMT films $n=3$ and data are given in mean \pm SD 


\section{In vitro permeation study}

Fig. 9 presents the results obtained from the in vitro permeation study of the films. The order of increased drug dissolution using the different approaches was as follows; CS-PPY/MMT-1>CS-PPY/MMT$2>$ CS-PPY/MMT-3 $>$ CS-PPY-4. Similar to the in vitro drug release effects, these results also clearly show that the CS-PPY/MMT-4 show the most sustained release effects as the release of the drug after $8 \mathrm{~h}$ of permeation study was $73.59 \% \pm 2.01 \%$. This phenomenon confirms that anionic exchange reaction occurred between CS and MMT and that consequently CS was intercalated into the MMT structure.

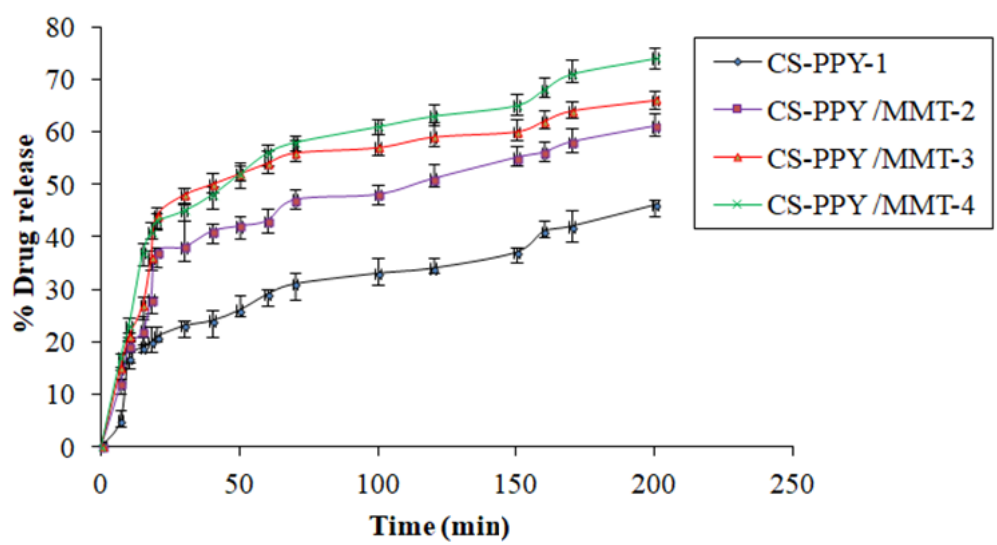

Fig. 9: In vitro permeation study of the CS-PPY/MMT films $n=3$ and data are given in mean \pm SD

\section{Determination of release kinetics}

The regression coefficient $\left(\mathrm{r}^{2}\right)$ values of Higuchi equation for CSPPY/MMT films CS-PPY-1, CS-PPY/MMT-2, CS-PPY/MMT-3 and CSPPY/MMT-4 were found to be $0.9927,0.9946,0.9837$ and 0.9778 respectively. To further confirm the mechanism of drug release from the CS/MMT films, the in vitro dissolution data were subjected to the Korsmeyer's Peppas equation. The values of the release exponent (n) were found to be ranging between 0.43 and 0.62 indicating a non-fiction (anomalous) drug release behavior.

Due to the swelling ability of the polymer, there is an opening of the pore channels in between the polymer matrix which helps with the diffusion of the drug through the polymer matrix chains, thus, releasing the drug from the films. Table 4 depicts the values of various release kinetics parameters for the films [10, 19-22].

Table 4: Release kinetic parameters of films of DOX (n=3)

\begin{tabular}{|c|c|c|c|c|c|c|c|c|c|c|c|}
\hline \multirow[t]{2}{*}{ Sample } & \multicolumn{2}{|c|}{ Zero-order } & \multicolumn{2}{|c|}{ First order } & \multicolumn{2}{|c|}{ Higuchi } & \multicolumn{3}{|c|}{ Korsmeyer peppas } & \multicolumn{2}{|c|}{ Hixon crowell } \\
\hline & $\mathbf{r}^{2}$ & $\mathbf{k}_{\mathbf{0}}$ & $\mathbf{r}^{2}$ & $\mathbf{k}_{\mathbf{0}}$ & $\mathbf{r}^{2}$ & $\mathbf{k}_{\mathbf{0}}$ & $\mathbf{r}^{2}$ & $\mathbf{n}$ & $\mathbf{k}_{\mathbf{0}}$ & $\mathbf{r}^{2}$ & $\mathbf{k}_{\mathbf{0}}$ \\
\hline CS-PPY-1 & 0.8734 & 0.1314 & 0.9831 & 0.0007 & 0.9927 & 2.7631 & 0.9921 & 0.4311 & 0.7343 & 0.9821 & 0.0016 \\
\hline CS-PPY/MMT-2 & 0.8579 & 0.1347 & 0.9421 & 0.0007 & 0.9946 & 2.8842 & 0.9932 & 0.4513 & 0.7231 & 0.9676 & 0.0015 \\
\hline CS-PPY/MMT-3 & 0.9142 & 0.1211 & 0.9641 & 0.0007 & 0.9837 & 2.9732 & 0.9767 & 0.5292 & 0.8143 & 0.9343 & 0.0013 \\
\hline CS-PPY/MMT-4 & 0.9453 & 0.1021 & 0.9713 & 0.0008 & 0.9778 & 2.5271 & 0.9323 & 0.6271 & 0.8937 & 0.9559 & 0.0018 \\
\hline
\end{tabular}

${ }^{*} \mathrm{CS}$ molecular weight in $\mathrm{kDa} . \mathrm{n}=3$ and data are given in mean \pm SD, Where CS: Chitosan, PPY: polypyrrole, MMT: Montmorilonite, DOX: Doxorubicin

\section{CONCLUSION}

The prepared nanocomposites were formulated using the solvent casting method. CS-PPY/MMT polymer composite was evaluated for physical parametric tests, tensile strength, moisture content, swelling, in vitro dissolution studies. The effect of MMT for enhancing mechanical and barrier properties of CS-PPY matrix has been noticed. This could be understood as due to a formation of filler network of MMT within the CS-PPY polymeric chains. The values of the tensile strength of CS-PPY/MMT film increased significantly with increasing MMT concentration, while the values of extensibility decreased for high values of MMT concentration. Additionally, doxorubicin-loaded CS-PPY/MMT nanocomposite can be of immense importance in the drug delivery. The combination of biodegradable polymeric chains and clay reinforcement can be applied to achieve the desired combination of properties (mechanical, swelling and controlled release) of materials used as a biosensor for diverse biomedical applications.

\section{ACKNOWLEDGMENT}

The authors thank the Central Institute of Plastics Engineering and Technology (CIPET), Odisha, India, and NRME Research Laboratory, Newredmars Education Pvt Ltd, Jagatsinghpur, Odisha, India for their support and using the facilities and instruments.

\section{AUTHORS CONTRIBUTIONS}

All the author have contributed equally

\section{CONFLICTS OF INTERESTS}

All authors have none to declare

\section{REFERENCES}

1. Tiwari G, Tiwari R, Sriwastawa B. Drug delivery systems: an updated review. Int J Pharm Investig 2012;2:2-11.

2. Yadav U, Husain N, Rehman Q. Formulation of nanoparticles of eprosartan mesylate for the better drug delivery by improving solubility. Asian J Pharm Clin Res 2018;11:260-3.

3. Rabinow BE. Nanosuspensions in drug delivery. Nat Rev Drug Discovery 2004;3:785-96.

4. Paluszkiewicz C, Stodolak E, Hasik M, Blazewicz M. FT-IR study of montmorillonite-chitosan nanocomposite materials. Spectrochim Acta A Mol Biomol Spectrosc 2011;79:780-4.

5. Chakra BK, Karan S, Das B, Debnath S, Chatterjee TK. A controlled release microsphere formulation of an anti-diabetic drug and characterization of the microsphere. Int J Pharm Pharm Sci 2018;10:30-8.

6. Rikhari B, Pugal Mani S, Rajendran N. Electrochemical behavior of polypyrrole/chitosan composite coating on $\mathrm{Ti}$ metal for biomedical applications. Carbohydr Polym 2018;189:126-37.

7. Khedr MA, Waly AI, Hafez AA. Synthesis of modified chitosanmontmorillonite nanocomposite. Aust J Basic Appl Sci 2012;6:216-26.

8. Kayan DB, Derya K, Merve İ. The activity of $p$ ani-chitosan composite film decorated with Pt nanoparticles for electrocatalytic hydrogen generation. Int J Hydrogen Energy 2016;41:10522-9. 
9. Günister E, Pestreli D. Synthesis and characterization of chitosan-MMT biocomposite systems. Carbohydrate Polymers 2007;67:358-65.

10. Thakur G, Singh A, Singh I. Formulation and evaluation of transdermal composite films of chitosan-montmorillonite for the delivery of curcumin. Int J Pharm Investig 2016;6:23-31.

11. Thakur G, Singh A, Singh I. Chitosan-montmorillonite polymer composites: formulation and evaluation of sustained release tablets of aceclofenac. Sci Pharm 2016;84:603-17.

12. $\mathrm{Xu} \mathrm{Y}$, Ren $\mathrm{X}$, Hanna MA. Chitosan/clay nanocomposite film preparation and characterization. Appl Polym Sci 2006; 99:1684-91.

13. Svoboda P, Zeng CC, Wang H, Lee LJ, Tomasko DL. Morphology and mechanical properties of polypropylene organoclay nanocomposites. J Appl Polym Sci 2002;85:1562-70.

14. Hasegawa N, Okamoto H, Kato M, Usuki A. Preperation and properties of ethylene propylene rubber (EPR)-clay nanocomposites based on maleic anhydride-modified EPR and organophilic clay. J Appl Polym Sci 2000;78:1918-23.

15. Bangyekan C, Aht-Ong D, Srikulkit K. Preparation and properties evaluation of chitosan-coated cassava starch films. Carbohydr Polym 2006;63:61-71.

16. Ferfera Harrar H, Dairi NA. Preparation of chatoyant-g-poly (acrylamide)/montmorillonite superabsorbent polymer composites: studies on swelling, thermal, and antibacterial properties. Appl Polymer Sci 2014;131:5-9.

17. Shafiu KA, Ismail M. In vitro delivery and controlled release of doxorubicin for targeting osteosarcoma bone cancer. Molecules 2013;18:45.

18. Yang H, Wang W, Zhang J, Wang A. Preparation, characterization, and drug-release behaviors of a $\mathrm{pH}$-Sensitive composite hydrogel bead based on guar gum, attapulgite, and sodium alginate. Int ] Polym Mater Polym Biomater 2012;62:369-76.

19. Kasirga Y, Oral A, Caner C. Preparation and characterization of chitosan/montmorillonite-K10 nanocomposites films for food packaging applications. Polym Compos 2012;33:1874-82.

20. Salcedo I, Aguzzi C, Sandri G, Bonferoni MC, Mori M, Cerezo P, et al. In vitro biocompatibility and mucoadhesion of montmorillonite chitosan nanocomposite: a new drug delivery. Appl Clay Sci 2012;55:131-7.

21. Depan D, Kumar AP, Singh RP. Cell proliferation and controlled drug release studies of nanohybrids based on chitosan-g-lactic acid and montmorillonite. Acta Biomater 2009;5:93-100.

22. Cojocariu A, Porfire L, Cheaburu C, Vasile C. Chitosan/ montmorillonite composites as matrices for prolonged delivery of some novel nitric oxide donor compounds based on theophylline and paracetamol. Cellulose Chem Technol 2012;46:35-43. 